\title{
Aspectos imunológicos e parasitológicos em Biomphalaria tenagophila infectadas por Schistosoma mansoni e outros Digenea*
}

\author{
Immunological and parasitological aspects of Biomphalaria tenagophila infected \\ by Schistosoma mansoni and other Digenea
}

\author{
Doralice de Souza Luro Balan**, Luiz Augusto Magalhāes***, Aquiles Eugênico Piedrabuena****
}

\begin{abstract}
BALAN, D. de S.L. et al. Aspectos imunológicos e parasitológicos em Biomphalaria tenagophila infectadas por Schistosoma mansoni e outros digenea. Rev. Saúde Pública, 27: 421-9, 1993. Estudou-se o comportamento de amebócitos de Biomphalaria tenagophila infectadas por Schistosoma mansoni, por outros Digenea e a resistência à superinfecção, presente em infecções mistas. Foi verificada a atividade fagocitária dos amebócitos, o número destas células circulantes, a reação amebocitária nos tecidos, o perfil eletroforético da hemolinfa, além da reação de imunodifusão. Concluiu-se que moluscos infectados por outros Digenea apresentam resistência à superinfecção por $S$. mansoni, sendo que os amebócitos parecem não ter participação direta na destruição dos esporocistos de $S$. mansoni nesta eventualidade. Nos moluscos infectados observou-se maior número de amebócitos circulantes e aumento de capacidade fagocitária destas células.
\end{abstract}

Descritores: Biomphalaria, parasitologia. Schistosoma mansoni.

\section{Introdução}

A grande maioria das investigações sobre a esquistossomose mansônica na região Neotropical utiliza a Biomphalaria glabrata como modelo de agente transmissor, provavelmente porque este molusco ajustou-se muito bem à condição de vetor do Schistossoma mansoni na América do Sul e no Caribe. Poucas investigações têm sido realizadas utilizando Biomphalaria tenagophila ou Biomphalaria straminea.

Tanto no campo (Magalhãcs ${ }^{27}$ ) como em laboratório (Magalhães ${ }^{28}$ ), B. tenagophila mostrou-se

\footnotetext{
* Trabalho realizado com auxúlio financeiro da Fundação de Amparo à Pesquisa do Estado de São Paulo (FAPESP) - Processo $n^{2}$ 88.2336.2.

** Bolsista da FAPESP (Processo $n^{9}$ 84.2132-7) junto ao Departamento de Parasitologia do Instituto de Biologia da Universidade Estadual de Campinas (UNICAMP) Campinas, SP - Brasil

*** Departamento de Parasitologia do Instituto de Biologia da Universidade Estadual de Campinas (UNTCAMP) Campinas, SP - Brasil

**** Departamento de Genética do Instituto de Biologia da Universidade Estadual de Campinas (UNICAMP) . Campinas, SP - Brasil
}

Scparatas/Reprints: D. de S.L. Balan - Caixa Postal 6109 UNICAMP - 13083-970 - Campinas, SP Brasil

Edição subvencionada pela FAPESP. Processo Medicina 93/ $0208-5$. pouco susceptivel à infecção esquistossomótica, apresentando, além de baixa taxa de infecção, número médio reduzido de cercárias por molusco, provavelmente devido à eficiência dos mecanismos de defesa do molusco (Guaraldo e col. ${ }^{16}, 1981$ ).

Alćm de ter de vencer a resistência natural à infecção oferecida pelo molusco, as larvas de $S$. mansoni podem enfrentar outros fatores que se intcrpōem ao seu desenvolvimento no interior do hospedeiro intermediário. Lim \& Heyneman ${ }^{21}$ (1972), referiram a existência de competição entre larvas de diferentes digenéticos no interior de moluscos planorbídeos. Esta competição poderia ocorrer por dois mecanismos: direto - predação por rédias que se alimentariam de esporocistos ou cercárias rivais; e indireto - elaboração de substâncias tóxicas às outras larvas, luta por espaço vital, competição alimentar, mecanismos imunológicos e perturbações no equilíbrio hospedeiro-parasito.

Ratchiffe e col. ${ }^{35}$ (1985) assinalaram o papel dos mecanismos de defesa celular e humoral prescntes nos moluscos. A defesa celular é mediada por amebócitos da hemolinfa e inclui processos de fagocitose, formação de granulomas, coagulação de hemolinfa e cicatrização. A defesa humoral inclui a presença e a ação de lisinas, aglutininas, fatores antimicrobianos e substâncias com ação semelhante às linfocinas. Em gastrópodos a resposta cclular foi demonstrada por Standen ${ }^{37}$ (1952), Cheng e col. ${ }^{12}$ (1970), Tripp ${ }^{43}$ (1970), Michelson $^{31}$ (1975) e Abdul-Salam e Michelson ${ }^{1}$ (1980). 
Em 1961 e 1970, Tripp ${ }^{41,43}$ verificou em $B$. glabrata a capacidade dos amebócitos de distinguirem material "próprio" do "não-próprio". Esses moluscos aceitaram implante de tecido homólogo, porém rejeitaram tecido heterólogo.

Mecanismos humorais estudados por Mackin ${ }^{29}$ (1961), Feng ${ }^{14}$ (1962) e Michelson ${ }^{30}$ (1963), revelaram fatores biologicamente ativos da hemolinfa que funcionalmente simulavam anticorpos. Vários fatores ativos da hemolinfa foram identificados como opsoninas que iniciariam ou facilitariam o processo de fagocitose (Tripp $\left.{ }^{42}, 1966\right)$.

Lie e col. ${ }^{19}(1976)$ assinalaram resistência adquirida em $B$. glabrata à infecção por $S$. mansoni. Bayne e col. ${ }^{7}$ (1984) verificaram a presença de receptores específicos para esporocistos primários de $S$. mansoni em amebócitos de $B$. glabrata.

A verificação de antagonismos entre larvas de Digenea que parasitam um mesmo molusco tem sido assinalada no Brasil (Machado e col.25,26, 1987, 1988). Esse fato tcm importância epidcmiológica como assinalaram $\mathrm{Lim}$ e Heyneman ${ }^{21}$ (1972), sugerindo que esses fenômenos competitivos fossem utilizados no combate ao $S$. mansoni no campo. Para isso scriam utilizados larvas de digenéticos rivais que predariam ou destruiriam os esporocistos ou cercárias de $S$. mansoni.

No presente trabalho avaliou-se a atividade fagocitária dos amebócitos nos moluscos parasitados, a formação de reações amebocitárias em torno das larvas infectantes, além da determinação do número de amebócitos na hemolinfa e a análise da imunodifusão e da imunoeletroforese da hemolinfa dos moluscos.

\section{Material e Método}

\section{Procedência dos moluscos}

Os 2.243 exemplares de $B$. tenagophila utilizados foram provenientes de Louveira, SP, capturados $\mathrm{cm}$ tanques de piscicultura. Esse local nunca foi apontado como foco de esquistossomose. Em alguns experimentos, por motivos de planejamento, utilizaram-sc 68 exemplares de $B$. tenagophila, nascidas e criadas em laboratório, descendentes de exemplares coletados no Valc do Rio Paraíba do Sul, SP.

\section{Verificaçâo da taxa de infecção natural}

Após a captura os moluscos foram expostos à luz e ao calor para a eliminação de cercárias (Pellegrino e col. ${ }^{34}, 1955$ ). Tal exposição foi repetida a cada 4 dias por um periodo de 60 dias. Os excmplares que não climinaram cercárias durante esse período e não apresentaram sinais visíveis de esporocistos à lupa estereoscópica, foram considerados livres de infecção. As cercárias foram identificadas pelo critério adotado por Machado e col. ${ }^{25}$ (1987), sendo os moluscos infectados separados por grupos, conforme o tipo de cercária eliminada. Os moluscos foram mantidos em frascos com água sem cloro e alimentados com alface.

\section{Constituição dos grupos de moluscos}

Grupo A - Moluscos B. tenagophila capturados em Louveira, SP

1A - Moluscos livres de infecção por digenéticos.

$2 \mathrm{~A}$ - Moluscos infectados por furcocercárias longifurcadas sem ocelos.

3A - Moluscos infectados por furcocercárias longifurcadas com $\propto$ celos.

4A - Moluscos infectados por equinostomocercárias.

$5 \mathrm{~A}$ - Moluscos infectados por xifidiocercárias.

$6 \mathrm{~A}$ - Moluscos naturalmente infectados por furcocercárias longifurcadas sem ocelos ou por equinostomocercárias ou ainda por xifidioccrcárias e superinfectadas por S. mansoni.

GrupoB - B.tenagophila nascidos em laboratório

1B - Moluscos livres de infecção.

2B - Moluscos infectados experimentalmente por S. mansoni.

Infecção experimental de B. tenagophila por $S$. mansoni

A infecção dos planorbídeos em laboratório foi realizada pela técnica de Standen ${ }^{37}$ (1952). Os moluscos foram infectados pela linhagem SJ de $S$. mansoni. Os miracídios foram obtidos de ovos de fezes de camundongos Swiss SPF. Os moluscos destinados à climinação de cercárias foram expostos, isoladamente, a 10 miracídios, e os destinados à observação histológica, a 100 miracídios.

\section{Exame histopatológico dos moluscos}

Exemplares de $B$. tenagophila naturalmente infectados por furcocercárias longifurcadas sem ocelos ou por equinostomocercárias ou ainda por xifidiocercárias foram submetidos, individualmente, a superinfecção com 100 miracídios de $S$. mansoni SJ e sacrificados por imersão em fixador Bouin alcoólico 24, 48 e 72 horas após a superinfeç̧ão.

Utilizaram-se 4 moluscos para cada tipo de infecção. As peças foram submetidas a cortes scriados com $7 \mu \mathrm{m}$ de espessura e coradas pelo Tricrômico de Gomori. 


\section{Obtenção e armazenamento da hemolinfa}

A hemolinfa foi colhida na região céfalo-podal do molusco, por rompimento do tegumento com estilcte, recolhendo-se com pipeta Pastcur, o material extravasado. Foram utilizados moluscos de 9 a $12 \mathrm{~mm}$ de diâmetro $\mathrm{e} o$ volume obtido foi de 20 a $30 \mu l$ de hemolinfa por espécime. Para obtenção de hemolinfa livre de células, foi a mesma submetida à centrifugação a $800 \mathrm{~g}$, por $10 \mathrm{~min}$. A hemolinfa colhida dos moluscos dos grupos A c $B$ foi utilizada para a dosagem de proteínas, contagem de amebócitos, ensaios de fagocitose e testes imunológicos.

\section{Teor protéico da hemolinfa}

As concentraçōes protéicas da hemolinfa foram estudadas utilizando-se os métodos de Biureto (Weichselbaum ${ }^{44}$ (1946) c Lowry e col. ${ }^{24}$ (1951). modificado. $O$ método de biureto foi utilizado quando a hemolinfa foi proveniente de três "pools" de 30 moluscos constituidos de: 1) $B$. tenagophila de laboratório livres de infecção (controle) - 2) $B$. tenagophila do campo livres de infecção (controlc) c 3) B. tenagophila de laboratório infectadas por $S$. mansoni. O método de Lowry e col. ${ }^{24}$ (1951), foi utilizado para hemolinfa fresca, colhida individualmente de exemplares dc: $B$. tenagophila do campo livres de infecção; $B$. tenagophila do campo infectadas por furcocercárias; $B$. tenagophi$l a$ do campo infectadas por xifidiocercárias $\mathrm{e} B$. tenagophila do campo infectadas experimentalmente com S. mansoni.

Obtenção de soro imune de coelho, anti-B. tenagophila do campo livre de infecção por digenéticos

O esquema de imunização adotado foi o de Oliveira $^{32}$ (1975) modificado. Foi injetada $\mathrm{em}$ coctho, hemolinfa de moluscos de campo livres de infecção por digenéticos, centrifugada a $17.000 \mathrm{~g}$, por $2 \mathrm{~min}$. As duas primciras inoculaçōes foram feitas nos gânglios poplítcos, com intervalo de 30 dias. A hemolinfa, em concentração protéica de $10 \mathrm{mg} / \mathrm{ml}$, foi cmulsionada com adjuvante completo de Freund, utilizando-se um volume total de $1 \mathrm{ml}$ dessa concentração cm cada inoculação. Após 15 dias da segunda inoculação, fez-se uma séric de quatro injeçōcs subcutâncas no dorso do animal, em intervalos semanais. Nessas inoculações a hemolinfa não foi emulsionada com adjuvante complcto de Frcund e a concentração protéica foi de $5 \mathrm{mg} / \mathrm{ml}$. Foram rcalizadas sangrias no coelho nos intervalos das injeçб̄es para verificação, por imunodifusão radial, do lítulo de anticorpos produzidos.

\section{Imunodifusão radial dupla}

Os experimentos de imunodifusão foram realizados em gel de ágar a $1 \%$ em solução salina $0,15 \mathrm{M}$, segundo indicaçðes de Ouchterlony ${ }^{33}$ (1958). A difusão ocorreu em temperatura ambiente por 30 a 40 h. Por meio da precipitação de agregados antígeno-anticorpo, foi analisado 0 perfil da hemolinfa $(\mathrm{Ag})$ frente ao soro imune do coclho (Ac) anti-hemolinfa. A coloração das lâminas fez-se pelo Coomassie-Blue. Foram utilizadas nas preparações somente hemolinfa dos grupos de $B$. tenagophila, capturadas no campo em Louveira, SP.

\section{Eletroforese e imunoeletroforese}

Foi utilizada a técnica de eletroforese e imunoeletroforese unidimensionais (Grabar \& Burtin ${ }^{15}$, 1964), utilizando-se lâminas de $10 \times 10 \mathrm{~cm}$ com agarose a $1 \%$ em tampão barbital 0,05M, pH 8,6. A elctroforese foi rcalizada a $4^{\circ} \mathrm{C}$, por $2 \mathrm{~h}$ com gradiente de potencial de $6 \mathrm{~V} / \mathrm{cm}$. Logo após a corrida eletroforética, efetuou-se a imunodifusão dos componentes separados frente a soro imune de coelho, em câmara úmida, a temperatura ambiente, por 30 a $40 \mathrm{~h}$. A coloração fez-se por Coomassie-Blue.

Foi estudada a hemolinfa de moluscos capturados no campo, parasitados e não parasitados por trematódeos.

\section{Contagem de amebócitos de hemolinfa}

A contagem foi realizada utilizando-se câmara de Neubaucr. Algumas contagens foram feitas em hemolinfa colhida de um "pool" de cinco moluscos, e em outras ocasiões as determinações foram individuais. Foi utilizada hemolinfa colctada na região céfalo-podal de moluscos com 10 a $12 \mathrm{~mm}$ de diâmetro. Os exemplares destinados a esse estudo foram $B$. tenagophila de campo, livres de infecção; $B$. tenagophila infectadas por furcocercárias sem occlo; $B$. tenagophila infectadas por xifidioccrcárias; $\mathrm{e} B$. tenagophila infectadas experimentalmente com $S$. mansoni.

\section{Avaliaçāo quantilativa da fagocitose}

A capacidade de fagocitose dos amebócitos de hemolinfa fresca dos moluscos foi avaliada frente a eritrócitos de carneiro formolizados. Para a rcalização dos ensaios "in vitro", tomou-se como base a técnica de Abdul-Salam \& Michclson ${ }^{1}$ (1980). A formolização de eritrócitos de carneiro, suspensos em Alsever, fez-se após lavagens com PBS pH 7,0 , adicionando-se a seguir 10 volumes de formol $3 \%$ à papa de eritrócitos. Dcixou-se a mistura por 
$24 \mathrm{~h}$ em agitação na geladeira. Novas lavagens em PBS e MEM (meio de Eagle) foram executadas. A suspensão foi ajustada para $7 \times 10^{4} \mathrm{cels} / \mathrm{mm}^{3}$. Para o preparo de monocamadas, a hemolinfa de um "pool" de 10 moluscos com 9 a $12 \mathrm{~mm}$ de diâmetro foi acondicionada em tubo de ensaio e mantida em banho gelo até sua utilização. Colocou-se $25 \mu \mathrm{l}$ de hemolinfa sobre lamínulas de vidro e incubou-se em câmara úmida por $20 \mathrm{~min}$ a $22^{\circ} \mathrm{C}$. Por inclinação das lamínulas, a hemolinfa foi removida, obtendo-se uma camada de amebócitos firmemente aderida. Para os ensaios de fagocitose de eritrócitos, as monocamadas foram cobertas com $25 \mu l$ de suspensão de eritrócitos de cameiro formolizados. Fez-se incubação em câmara úmida por uma hora a $22^{\circ} \mathrm{C}$. Ao final, os eritrócitos em excesso foram removidos por lavagem em MEM $\mathrm{pH}$ 7,5. As laminulas foram fixadas com álcool metílico por $5 \mathrm{~min}$, coradas com Giemsa $1: 5 \mathrm{e}$ montadas em lâminas para microscopia. $\mathrm{O}$ grau de fagocitose foi determinado pela contagem ao acaso de um mínimo de 200 amebócitos em cada monocamada, utilizando-se para tanto microscópio óptico. A capacidade de fagocitose dos amebócitos foi avaliada nos grupos $B$. tenagophila de campo, livres de infecção, infectada por furcocercárias sem ocelo, infectadas por xifidioccrcárias e $B$. tenagophila de campo infectadas experimentalmente com $S$. mansoni.

\section{Análise estatística}

Utilizaram-se métodos estatísticos para análise dos valores obtidos nas dosagens protécas de hemolinfa, nas contagens de células "sprecdings" da hemolinfa fresca e na avaliação quantitativa da fagocitose. A análise desses fatores foi efeluada pclo teste de Student e pela análise de variância (testes de Bartlet, Cochran e Tukey). Para algumas situações optoụ-se por testes não paramétricos, como os testes de Kruskal-Wallis e MaunWithney (IJ test) (Roscoc ${ }^{36}, 1975$ ). Muitos valores exigiram transformaçð̃cs matcmáticas, ou scja, foram normalizados para screm usados no teste de Tukey (Campos $\left.{ }^{13}, 1979\right)$.

\section{Resultados}

\section{Taxa de infecçāo natural dos moluscos}

A taxa de infeç̧ão natural dos moluscos (Tabcla 1) foi calculada para os quatro tipos de ccrcárias encontradas: furcoccrcárias longifurcadas $5 \mathrm{~cm}$ ocelos, furcocercárias longifurcadas com occlos, equinostomocercárias e xifidiocercárias. Não foram constatadas infecções concomitantes
Tabela 1. Número de exemplares de B. tenagophila por tipos de cercárias $\theta$ taxa de infecção natural.

\begin{tabular}{lcc}
\hline Tipos de cercária & $\begin{array}{c}\text { Número de } \\
\text { exemplares }\end{array}$ & $\begin{array}{c}\text { Percentual de } \\
\text { infecçäo }\end{array}$ \\
\hline $\begin{array}{l}\text { Furcocercárias } \\
\text { longifurcadas sem ocelos }\end{array}$ & 122 & 5,4 \\
$\begin{array}{l}\text { Furcocercárias } \\
\text { longifurcadas com ocelos }\end{array}$ & 11 & 0,5 \\
Equinostomocercárias & 7 & 0,3 \\
Xifidiocercárias & 62 & 2,8 \\
\hline
\end{tabular}

por mais de um tipo de cercária. Em 2.041 exemplares não foi observada eliminação de cercárias.

\section{Reaçōes teciduais e presença de larvas nos tecidos dos moluscos}

Nos cortes histológicos foram observados esporocistos, rédias e cercárias. A superinfecção por $S$. mansoni não determinou a destruição ou a parada do crescimento das larvas de outros trematódeos que anteriormente parasitavam os moluscos, tendo sido encontrados esporocistos íntegros contendo furcocercárias, equinostomocercárias e xifidiocercárias. Nos exemplares superinfectados por $S$. mansoni, os esporocistos de $S$. mansoni foram destruídos, apresentando-se como uma massa amorfa, sem células individualizadas. Em torno das larvas destruídas não foram observadas reações amebocitárias.

\section{Observaçōes referentes a hemolinfa}

Os resultados referentes a dosagens de proteína (Tabela 2) mostraram uma diferença altamente significativa entre o grupo de moluscos capturados no campo e o grupo nascido e criado no laboratório, infectados e não infectados.

A infecção por digenéticos nạo altcrou o valor protéico na hemolinfa.

Tabela 2. Dosagem de proteína total da hemolinfa de B. tenagophila.

\begin{tabular}{|c|c|c|c|}
\hline \multirow{2}{*}{$\begin{array}{l}\text { Procedência dos moluscos } \\
\text { Do campo, livres de infecção } \\
\text { Do laboratório, livres de infecção } \\
\text { Do laboratório, infectados por }\end{array}$} & \multirow{2}{*}{$\begin{array}{l}\text { Método } \\
\text { Biureto } \\
\text { Biureto }\end{array}$} & \multicolumn{2}{|c|}{$\begin{array}{c}\text { Dosagem } \\
(\mathrm{mg} / \mathrm{ml})\end{array}$} \\
\hline & & & $\begin{array}{l}2,72 \\
7,36\end{array}$ \\
\hline $\begin{array}{l}\text { S. mansoni } \\
\text { Do campo, livres de infecção } \\
\text { Do campo, experimentalmente }\end{array}$ & $\begin{array}{l}\text { Biureto } \\
\text { Lowry }\end{array}$ & $\begin{array}{l}44,97 \\
27,86\end{array}$ & $\begin{array}{l}5,77 \\
6,41\end{array}$ \\
\hline $\begin{array}{l}\text { infectadas por } S \text {. mansoni } \\
\text { Do campo, infectados por }\end{array}$ & Lov & 33,90 & 2,40 \\
\hline $\begin{array}{l}\text { urcocercárias sem ocelos } \\
\text { Do campo, infectados por }\end{array}$ & Lowry & 25,09 & 4,63 \\
\hline jiocercárias & Lowry & 27,88 & 1,21 \\
\hline
\end{tabular}




\section{Contagem de amebócitos e avaliação da fagocitose}

As contagens de amebócitos foram feitas individualmente por molusco (Tabela 3) e em "pool" de 5 moluscos (Tabela 4). Todos os exemplares examinados foram moluscos capturados no campo.

Os dados da Tabela 4 mostram que houve aumento significativo do número de amebócitos nos moluscos infectados por digenéticos. Os moluscos infectados por xifidiocercárias foram os que apresentaram maior número de amebócitos circulantes.

Tabela 3. Número médio de amebócitos na hemolinfa fresca, sem diluição, feita individualmente em exemplares de $B$. tenagophila.

\begin{tabular}{lcrc}
\hline Procedência do molusco & \multicolumn{2}{c}{$\begin{array}{c}N^{2} \text { de células } \\
\text { "spreading } / \mathrm{mm}^{3 n}\end{array}$} \\
\hline $\begin{array}{l}\text { Do campo, livres de infecção } \\
\text { Do campo, infectados }\end{array}$ & 17 & 8,60 \\
experimentalmente por $S$. mansoni & 22 & 12,10 \\
\hline
\end{tabular}

Tabela 4. Número médio de amebócitos em "pool" de hemolinfa fresca, de B. tenagophila.

\begin{tabular}{lcc}
\hline Procedência do molusco & \multicolumn{2}{c}{$\begin{array}{c}N^{2} \text { de células } \\
\text { "spreading/mm }\end{array}$} \\
\hline $\begin{array}{l}\text { Do campo, livres de infecção } \\
\text { Do campo, experimentalmente }\end{array}$ & 17 & 1,29 \\
infectados por S. mansoni & 21 & 2,08 \\
$\begin{array}{l}\text { Do campo, infectados por } \\
\text { furcocercárias }\end{array}$ & 21 & 0,95 \\
$\begin{array}{l}\text { Do campo, infectados por } \\
\text { xifidiocercárias }\end{array}$ & 22 & 0,95 \\
\hline
\end{tabular}

A capacidade de fagocitose apresentada pclos amebócitos foi maior nos grupos infectados por trematódeos digenéticos, excluindo-se S. mansoni. O grupo que aprescntou maior capacidade de fagocitose foi o infectado por xifidioccrcárias (Tabela 5).

Tabela 5. Taxa de fagocitose dos amebócitos da hemolinfa de $B$. tenagophila frente a eritrócitos de carneiro formolizados.

\begin{tabular}{llll}
\hline Procedência dos moluscos & \multicolumn{2}{c}{$\begin{array}{c}\text { Fagocitose } \\
(\%)\end{array}$} & $x^{*}$ \\
\hline Do campo, livres de infecção & 59,4 & 5,98 & 50,452 \\
$\begin{array}{l}\text { Do campo, experimentalmente } \\
\text { infectados por S. mansoni }\end{array}$ & 60,0 & 1,58 & 50,768 \\
$\begin{array}{l}\text { Do campo, infectados por } \\
\text { furcocercárias }\end{array}$ & 76,4 & 4,77 & 65,874 \\
Docampo, infectados por & 83,2 & 3,11 & 61,23 \\
\hline xifidiocercárias & &
\end{tabular}

Todos os valores foram significativos ao nivel de $0,1 \%$ pelo teste de Tukey.

- A média representa os valores transformados pela fórmula: $x+0.5$

\section{Teste imunologicos}

Todos os testes imunológicos foram realizados, pelo menos, em triplicatas.

A hemolinfa de $B$. tenagophila foi um antígeno adequado para a preparação de soro imune em coelhos. $O$ exame de imunodifusão mostrou título de 1:4, 40 dias após a primeira inoculação nos gânglios poplíteos do animal, sendo logo após iniciadas as inoculaçz̃es no dorso. No final do esquema de imunização, o título obtido foi de 1:32.

Utilizando-se o teste de precipitação em gel de ágar, verificou-se que houve uma identidade total entre os antígenos de todas as amostras analisadas. Os sistemas antígeno-anticorpo ao reagirem originaram, pelo menos, 3 bandas de precipitação muito nítidas. Como não se observaram diferenças antigênicas entre a hemolinfa do grupo de camundongos do campo infectados e livres de infccção, observou-se identidade total das linhas de precipitação.

O perfil imunoelctroforético foi obtido dos vários grupos experimentais. A migração das proteínas foi em direção ao pólo catódico. Nas preparações a fresco, nas amostras de hemolinfa de $B$. tenagophila livres de infecção, foi encontrada uma banda tênue, próximo ao poço central que migrou em direção ao pólo anódico. Esta banda, entretanto, foi removida facilmente pela lavagem do gel em salina, antes da secagem $c$ coloração.

Foram encontradas na hemolinfa de $B$. tenagophila livre de infecção, linhas de precipitação, scndo uma deslocada para o pólo anódico, uma junto ao próprio poço de depósito da amostra, duas próximas ao poço em direção ao pólo catódico $\mathrm{c}$ uma última, muito densa, deslocando-se rapidamente, tendo percorrido maior distância em direção ao pólo positivo.

Quando se submetcu a hemolinfa de $B$. tenagophila infectada por furcocercárias à imunocletroforese obtiveram-se 4 linhas deslocando-se $\mathrm{cm}$ direção ao pólo positivo. Entre clas, uma mais forte e densa, deslocou-se mais rapidamente.

Também foram vistas 4 linhas de precipitação quando se utilizou hemolinfa de $B$. tenagophila infectada por $S$. mansoni, uma delas apresentando-se muito densa e migrando rapidamente.

$\mathrm{Na}$ hemolinfa de $B$. tenagophila infectada por xifidiocercárias, detectaram-se 3 linhas de precipitação deslocando-se em direção ao pólo positivo, sendo que a de maior densidade migrou mais rapidamente.

Provavelmente, em todos os testes, a banda mais densa abrigava vários agregados antígenoanticorpo sobrepostos. 


\section{Discussáo}

Vários autores verificaram resistência à infecção em moluscos sensibilizados por infecç̋̃es prévias. Sullivan e col. ${ }^{40}$ (1982) indicaram indução de resistência adquirida em $B$. glabrata sensibilizada por miracídios irradiados de Ribeiroia marini, tendo estes moluscos adquirido resistência à reinfecção quando expostos a miracídios não irradiados. Essas larvas foram destruídas por amebócitos, tendo havido aumento do número dessas células. Jourdane \& Mounkas$\mathrm{sa}^{17}$ (1986) descreveram competição intraespecífica entre os esporocistos primários de $S$. mansoni e de Echinostoma caproni, quando coabitavam com $B$. pfeifferi. Houve degeneração de uma geração significativa de esporocistos primários de $S$. mansoni, sendo que a fração restante migrou para fora de seus microbiótopos preferidos, provavelmente para locais não imunologicamente ativos.

Nos exames histopatológicos verificou-se nas superinfecçб̃es total degencração dos esporocistos primários de $S$. mansoni, tendo os esporocistos de todas as outras espécies de digenélicos permanecido íntegros. Houve evidentemente proteção à superinfeç̧ão por $S$. mansoni.

Lic e col. ${ }^{20}$ (1980) descreveram as reaçócs teciduais induzidas por $S$. mansoni $\mathrm{em} B$. glabrata susceptívcis, expostas previamente a miracídios mediados de $E$. paraensei, c notaram esporocistos de $S$. mansoni degencrados sem reação amcbocitária ou com número muito reduzido dessas células presas aos esporocistos. Constatou-sc a ausĉncia de reação amebocitária aparente em tomo dos esporocistos destruídos de $S$. mansoni cm todas as superinfecções realizadas, o que pode significar a ação de fatores humorais na destruição do parasito. Bayne e col. ${ }^{5,6}$ (1980) relataram que fatores na hemolinfa (excluindo-se as células) de B. glabrata estariam envolvidos na destruição dos parasitos pelo hospedeiro intermediário. Loker \& Bayne 22 (1982) demonstraram em estudos "in vitro" com B. glabrata componentes da hemolinfa (fatores humorais ou fatores do plasma) de excmplares resistentes que destruíram esporocistos de $S$. mansoni quando incubados com o parasito. Bayne c col. ${ }^{8}$ (1985) postularam que os componentes do plasma que medeiam a defesa celular $\mathrm{cm} B$. glabrata são aglutininas com conformação molecular específica c que reconheceriam diferenças entre espécies distintas de caramujos. Bayne c col. ${ }^{9}$ (1986) demonstraram aglutininas na resposta de defesa dos moluscos com papcl opsônico na fagocitose "in vitro".

Loker \& Hertcl $^{23}$ (1987) cvidenciaram diferenças na quantidade de proteína total na hemo- linfa de $B$. glabrata, parasitado por $E$. paraensei, sendo que esse valor aumenta muito nos caramujos susceptiveis. Nos exemplares não infectados, o valor protéico foi maior que nos exemplares infectados por $S$. mansoni. Quando se comparou com moluscos capturados no campo, os moluscos nascidos e mantidos em laboratório, apresentaram valores maiores de proteinas na hemolinfa. Tal situação, talvez deva-se a fatores como alimentação e confinamento. Entre os grupos capturados no campo, verificou-se não haver diferença significativa entre eles, no que se refere ao teor protéico da hemolinfa, quer estejam ou não parasitados por trematódeos digenéticos. Provavelmente em $B$. tenagophila os valores de proteína na hemolinfa podem variar em razão da linha$\mathrm{gem}$ dos caramujos e da época de infeç̧ão. Estudos complementares poderão confirmar ou não esta hipótese.

Os presentes resultados na contagem de amcbócitos na hemolinfa (amebócitos circulantes) mostraram-se concordantes com os assinalados por Stumpe \& Gilbertson ${ }^{39}$ (1980). Esses autores definiram que granulócitos (cólulas fagociticamente ativas) expressaram aumento em númcro nos moluscos $B$. glabrata parasitados por $S$. mansoni, $\mathrm{cm}$ relação aos controles sem infecção. Vcrificou-se "in vitro" a atividade de fagocitose aumentada nos grupos infectados. Hipoteticamente pode-se admitir que o parasitismo ative as células fagocíticas, já que se sabc por Cheng \& Schocnberg ${ }^{11}$ (1980), que essas cćlulas são dependentes de fatores quimiotáxicos ou de falores de reconhecimento, e que o número participante dessas células na ingestão de partículas é de 30 a 100\% (Anderson \& Good $^{3}, 1976$ ). Os trabalhos de Yoshino ${ }^{45}$ (1982), Abdul-Salam \& Michelson ${ }^{45}$ (1983), Bayne e col. ${ }^{7}$ (1984) e Knapp e col. ${ }^{18}$ (1987) assinalaram os seguintes fatos: esporocistos são encapsulados e mortos por células semelhantes a macrólagos, os detcrminantes da superfície dos amcbócitos são modulados por lectinas; antígenos de $S$. mansoni reagem com amebócitos de $B$. glabrata e com receptores específicos para $S$. mansoni nos amebócitos de $B$. glabrata.

Alravćs da imunodifusão e da imunocletrolorese, vários trabalhos contribuíram para a diferenciação taxonômica de caramujos de importância médica (Bailcy c col. $\left.{ }^{4}, 1986\right)$; demonstraram glicoproteínas aglutinantes em $B$. glabrata para 0 sistema $A B O$ humano (Stanislawsky e col. ${ }^{38}$, 1976) e revelaram variedades de peptídeos $\mathrm{em}$ exemplares susceptíveis e resitentes da espécic $B$. glabrata (Bayne e col. ${ }^{9}, 1986$ ). Bayne e col. ${ }^{10}$ (1987) verificaram em $B$. glabrata que muitas macromoléculas componentes da hemolinfa são 
glicoprotcínas e a ampla maioria dos determinantes antigênicos são carboidratos. Loker \& Hertel $^{23}$ (1987) verificaram que componentes da hemolinfa de $B$. glabrata exibiam alterações moleculares quantitativas $\mathrm{e}$ qualitativas reveladas por SDS-PAGE*. Pelo perfil eletroforético obtido da hemolinfa dos moluscos infectados pelos diferentes trematódeos, foram encontradas alteraçōes que mostraram características específicas de cada diferente tipo de infecção. A coloração efetuada indicou a natureza protéica das bandas encontradas no gel. As imunodifusões e imunoeletroforeses permitiram afirmar que há diferenças qualitativas e quantitativas na hemolinfa de $B$. tenagophila do campo, parasitadas quando comparadas com a hemolinfa de moluscos do grupo controle, livres de infecção.

Como ocorre com qualquer animal capturado no campo, não se pode descartar a eventualidade de infecções prévias, já curadas, por outras espécics ou mesmo infecções abortadas. Esta é uma limitação do experimento que se acredita não scr muito relevante nos moluscos, pelo fato destes animais não apresentarem mecanismos imunes tão aperfeiçoados como o dos vertcbrados.

\section{Conclusões}

Biomphalaria tenagophila capturadas no campo, $\mathrm{cm}$ tanques de piscicultura, foram encontradas parasitadas, sempre em infecção única, por furcoccrcárias longifurcadas sem ocelo, furcocercárias longifurcadas com ocelo, equinostomocercárias ou xifidiocercárias.

Exemplares de $B$. tenagophila naturalmente parasitados por trematódcos c superinfectados experimentalmente por $S$. mansoni mostraram-sc resistentes ao desenvolvimento de esporocistos de $S$. mansoni.

Nos moluscos supcrinfectados com $S$. manso$n i$ não foram encontradas reaçōes amebocitárias $\mathrm{cm}$ torno dos esporocistos degenerados de $S$. mansoni. Essas observaçð̄es sugerem que não houve participação direta dos amebócitos na destruição da larva de $S$. mansoni e que possivelmente fatores da hemolinfa (excluindo-se as células), estariam envolvidos na destruição do parasita.

Os valores de proteínas totais de hemolinfa mostraram-sc maiores nos moluscos $B$. tenagophila $\mathrm{sem}$ infecção mantidos $\mathrm{em}$ laboratório, quando comparados com os capturados no cam-

* $\quad$ "Sodium dodecyl sulphate - polyacrylamide gel electrophoresis". po livres de infecção por trematódeos. Esses valores não estão aumentados nos caramujos de campo naturalmente parasitados, ou mesmo nos caramujos experimentalmente infectados com $S$. mansoni.

O número de amebócitos da hemolinfa estava elevado em todos os grupos de moluscos infectados.

Foi observada maior atividade fagocitária dos amebócitos recolhidos dos caramujos parasitados, principalmente dos parasitados por xifidiocercárias.

$\mathrm{Na}$ hemolinfa dos vários grupos estudados houve identidade antigênica total. As imunodifusões mostraram ao menos 3 linhas de precipitação, formando 3 sistemas diferentes.

Os resultados obtidos na imunoeletroforese permitem afirmar que existem diferenças qualitativas e quantitativas na hemolinfa dos moluscos parasitados com rclação aos não parasitados. As diferenças parecem ter características específicas dependentes do tipo de infecção apresentada.

BALAN, D. de S.L. et al. [Immunological and parasitological aspects of Biomphalaria tenagophila infected by Schistosoma mansoni and other Digenea]. Rev. Saude Pública, 27: 421-9, 1993. The behavior of Biomphalaria tenagophila amoebocytes was studied in infections produced by Schistosoma mansoni and other Digenea. The resistance to superinfection was also verified in mixed infections. Data on amoebocyte phagocylic activity, on the number of amoebocytes in hemolymph, and on amoebocyte tissue ractions were obtained and eletrophoretic and imunodiffusion examinations of the hemolymph were carried out. It was concluded that the snails infected with Digenea show resistance to superinfection with $S$. mansoni. Apparently sporocysts are not destroyed by the action of amoebocytes. An increase in amoebocyte phagocytic activity was discovered in infected snails. Immunoeletrophoresis shows quantitative and qualitative differences in the hemolymph of the infected snails.

Keywords: Biomphalaria, parasitology. Schistosoma mansoni.

\section{Referências Bibliográficas}

1. ABDUL-SALAM, J.M. \& MICHELSON, E.H. Biompha. laria glabrata amoebocytes assay of factors influencing in vitro phagocytosis. J. Invertebr. Pathol., 36: 529,1980 .

2. ABDUL-SALAM, J.M. \& MICHELSON, E.H. Schistosoma mansoni: immunofluorescente detection of its antigen reacting with Biomphalaria glabrata amoebocytes. Exp. Parasitol., 55: 132-7, 1983.

3. ANDERSON, R.S. \& GOOD, R.A. Opsonic involvement phagocytosis by mollusk hemocytes. J. Invertebr. Path. ol., 27: 57-64, 1976. 
4. BAIlEY, J.B.; MICHELSON, E.H.; PARAENSE, W.L. Differentiation of the sibling species Biomphalaria oc. cidentalis and Biomphalaria tenagophila by the electrophoretic pattems of their hemoglobin. Mem. Inst. Oswaldo Cruz, 81: 319-22, 1986.

5. BAYNE, C.J.; BUCKLEY, P.M.; DEWAN, P.C. Macrophagelike hemocytes of redistant $B$. glabrata are citotoxic for sporocysts of $S$. mansoni in vitro. J. Parasitol., 66: 413-19, 1980 (a)

6. BAYNE, C.J.; BUCKLEY, P.M.; DEWAN, P.C. S. mansoni citotoxicity of hemocytes form susceptible snail hosts for sporocystes in plasma resistant, $B$. glabrata. Exp. Parasitol., 50: 409-13, 1980.

7. BAYNE, C.J.; LOKER, E.S.; YUI, M.A.; STEPHENS, H.A Immune-recognition of $S$. mansoni primary sporocysts may require specific receptors on $B$. glabrata hemocytes. Parasite Immunol., 6: 519-28, 1984.

8. BAYNE, C.J.; BOSWELL, C.A.; LOKER, E.S.; YUI, M.A. Plasma components which mediate cellular defences in the gastropod mollusc B. glabrata. Dev. Comp. Immunol., 9: 523-30, 1985.

9. BAYNE, C.J.; LOKER, E.S.; YU, M.A. Interactions between the plasma proteins of $B$. glabrata (Gastropoda) and the sporocyst tegument of $S$. mansoni (Trematoda). Parasitology, 92: 653-64, 1986.

10. BAYNE, C.J.; BOSWELL, C.A.; YUI, M.A. Widespread antigenic cross-reactivity between plasma proteins of a gastropod and its trematode parasite. Dev. Comp. Immunol., 11: 321-29, 1987.

11. CHENG, T.C. \& SCHOENBERG, D.A. Phagocytic funnellike pseudopodia in lectin-treated gastropod hemocytes. J.Invertebr. Pathol., 36: 141-4, 1980.

12. CHENG, T.C. \& RIFKIN, E. Cellular reactions in marine molluses in response to helminth parasitism. Amer. Fish. Soc., 5: 443-96, 1970.

13. CAMPOS, H. Estat lstica experimental näo paramétrica. $3^{*}$ ed. Piracicaba, Dep. Matemática e Estatística ESALC USP, 1979

14. FENG, S.Y. The responses of oyesters to the introduction of soluble and pariculate materials and factors modifying the response. New Brunswick, N.J., 1962. [Doctoral Thesis - Rutgers University].

15. GRABAR, P. \& BURIN, P. Immunoelectrophoretic analysis. New York, Elsevier, 1964. p. 3-29, 94-124.

16. GUARALDO, A.M.A.; MAGALHĀES, L.A.; RANGEL, H. de A.; PAREJA, G. Evolução dos esporocistos de $S$. mansoni (Sambon, 1907) em B. glabrata (Say, 1818) e $B$. tenagophila (D'Orbigny, 1835). Rev. Saúde Pública, 15: $436-48,1981$.

17. JOURDANE, J. \& MOUNKASSA, J.B. Topographic shiffing of primary sporocysts of $S$. mansoni in Biomphalaria pfeifferi as a result of coinfection with Echinostomas ca. proni. J.Invertebr. Pathol., 48: 269-74, 1986.

18. KNAAP, W.P.W.; MEULEMAN, E.A.; SMINIA, T. Alterations in the internal defenses system of the pond snail Lymnaea stagnalis induced by infection with the schistosomose Trichobilharzia ocellata. Parasitol. Res., 73: $57-65,1987$.

19. LIE, K.J.; HEYNEMAN, D.; YAU, P. Studies on resistance in snails. 6. Escape of $E$. lindoense sporocysts from encapsulation in the snails heart and subsequent loss of the host's ability to resist infection by the same parasite. J. Parasitol., 62: 298-302, 1976.

20. LIE, K.J.; JEONG, K.H.; HEYNEMAN, D. Tissue reactions by $S$. mansoni in B. glabrata. Ann. Trop. Med. Parasitol., 74: 157-66, 1980.

21. LIM, M.K. \& HEYNEMAN, D. Intramoluscan inter trematode antagonism: a review of factors influencing the host-parasite system and its possible role in histological control. Adv. Parasirol., 10: 191-268, 1972.
22. LOKER, E.S. \& BAYNE, C. In vitro encounters between $S$. mansoni primary sporocysts and hemolymph components of susceptible and resistent strains of $B$. glabrata. Am. J. Trop. Med. Hyg., 31: 999-1005, 1982.

23. LOKER, E.S. \& HERTEL, L.A. Alterations in B. glabrata plasma induced by infection with the digenetic trematode Echinostoma paraensei. J. Parasitol., 73: 503-13, 1987.

24. LOWRY, O.H.; ROSENBROUGH, N.J.; FARR, A.L.; RANDALL, R.J. Protein measurement with the folin phenol reagent. J. Biol. Chem., 193: 265-75, 1951.

25. MACHADO, S.M.P.; CORDEIRO, N.S.; MAGALHĀES, L.A.; ARTIGAS, P.T. Algumas consideraçōes sobre cercárias naturalmente encontradas em $B$. tenagophila capturadas em Louveira, SP. Mem. Inst. Butantan, 49: 79-86, 1987.

26. MACHADO, S.M.P.; MAGALHAES, LA.; ARTIGAS, P.T.; CORDEIRO, N.S.; CARVALHO, J.F. Verificação de antagonismo entre larvas de $S$. mansoni e larvas de outros digenea em $B$. tenagophila molusco planorbídeo de criadouro natural situado na região de Campinas, SP, Brasil. Rev. Saúde Pública, 22: 484-8, 1988.

27. MAGALHÃES, L.A. Moluscos planorbídeos do Estado da Guanabara. Rev. Bras. Biol., 24: 277-88, 1964.

28. MAGALHÄES, L.A. Estudo dos dados obtidos de uma população de B. glabrata de Belo Horizonte infectada por $S$. mansoni da mesma cidade, e de uma população de $B$. tenagophila infectada por $S$. mansoni de São José dos Campos. Rev. Soc. Bras. Med. Trop., 3: 195. $6,1969$.

29. MACKIN, J.G. Oyster leukocytes in infections diseases (abstr.). Am. Zool., 1: 371, 1961.

30. MICHELSON, E.H. "Immune" reaction of $S$. mansoni in the snail Australorbis glabratus. J. Insect. Pathol., 5: 412-20, 1963.

31. MICHELSON, E.H. Cellular defense mechanisms and tissue alterations in gastropod molluscs. In: Maramorosch, K. \& Shope, R. E., ed. Invertebrate Immunity. Now York, Academic Press, 1975. p. 181-95.

32. OLIVEIRA, A.R. Consideraçōes sobre anti-soros obtidos pela técnica de injeçâo do antígeno no linfonódulo. Summa. Phytop, 1: 61, 1975.

33. OUCHTERLONY, O. Difusion-in-gel methods for immunological analysis. Prog. Allergy, 5: 1-78, 1958.

34. PELLEGRINO, J. \& MACEDO, D.G. A simplified method for the concentration of cercariae. J. Parasitol. 41: 329-30, 1955.

35. RATCLIFFE, N.A.; ROWLEY, A.F.; FITZGERALD, S.W.; RHODES, C.P. Invertebrate immunity: basic concepts and advance. Int. Rev. Citol., 97: 183-350, 1985.

36. ROSCOE, V.T. Fundamental research statistics the behavioral sciences. 2 ed. New York. Hort. Richard and Winstou. INC, 1975.

37. STANDEN, O.D. Experimental infection of Australorbis glabratus with $S$. mansoni - I. Individual and mass in. fection of snails and the relationship of infection temperature and season. Ann. Trop. Med., 44: 48-53, 1952.

38. STANISLAWSKI, E; RENWRANTZ, L.; BECKER, W, Soluble blood group reative substances in the hemolymph of B. glabrata (Mollusca). J. Invertebr. Pathol., 28: $301-8,1976$

39. STUMPE, J.L. \& GILBERTSON, D.E. Differential leukocytic responses of $B$. glabrata to infection with $S$. mansoni. J. Invertebr. Pathol, 35: 217-18, 1980.

40. SULLIVAN, J.T.; RICHARDS, C.; LIE, K.J.; IIEYNEMAN, D. Ribeiroia marini: irradiated miracidia and introduction of adquired resistance in B. glabrata. Exp. Parasitol., 53: 17-25, 1982. 
41. TRIPP, M.R. The fate of foreign materials experimentally introduced into the snail Australorbis glabratus. J. Pa. rasitol., 47: 745-51, 1961.

42. TRIPP, M.R. Hemagglutinin in the blood of the oyster Crassostrea virginica. J. Invertebr. Pathol., 8: 478-84, 1966.

43. TRIPP, M.R. Defense mechanism of mollusks. J. Retic. Endoth. Soc., 7: 173-82, 1970.

44. WEICHSELBAUM, T.E. An accurate and rapid method for the determination of protein in small amont of blood serum and plasma. Am. J. Clin. Palhol. Technol., 10: $40,1946$.

45. YOSHINO, T.P. Lectin-induced modulation of snail hemocytes surface determinants: clearense of con a receptor complexes. Dev. Comp. Immunol., 6: 451-61, 1982.

Recebido para publicaçāo em 25.3.1993

Reapresentado em 8.9.1993 Aprovado para publicaçäo em 20.9.1993 